\title{
"LITERATURA É ÓCIO": DIMENSÕES ESTÉTICAS DO MODELO ACADÊMICO NA LITERATURA BRASILEIRA DO INÍCIO DO SÉCULO XX
}

\section{"LITERATURE IS IDLENESS": AESTHETIC DIMENSIONS OF THE ACADEMIC MODEL IN THE BRAZILIAN LITERATURE OF THE BEGINNING OF THE XX CENTURY}

\author{
Recebido: 11/05/2020 | Aprovado: 25/05/2020 | Publicado: 10/07/2020 \\ DOI: https://doi.org/10.18817/rlj.v4i1.2217
}

Maurício Silva $^{1}$
Orcid ID:http://orcid.org/0000-0002-9609-4579

Resumo: O presente artigo analisa o contexto cultural do pré-modernismo brasileiro, destacando o processo de canonização do autor pela historiografia literária e revela outros aspectos estéticos e literários da Literatura Brasileira. Além disso, este artigo analisa as possíveis relações entre autores pré-modernistas e a Academia Brasileira de Letras, durante a passagem do século XIX para o XX.

Palavras-chave: Pré-Modernismo. Literatura Brasileira. canonização. historiografia literária.

Abstract: The present article analyses the cultural context of brazilian pre-modernism, and points out the process of canonization by the literary historiography, and it reveals some aesthetic and literary aspects of Brazilian Literature. Furthermore, the present article analyzes the relationship between the pre-modernist writers and the Brazilian Academy of Letters, detaching the institutionalizations issues on the turn-of-the-century.

Keywords: Pre-Modernism. Brazilian Literature. canonization. literary historiography.

Literariamente falando, a passagem do século XIX para o XX foi marcada por uma visão mais ou menos padronizada das artes, perspectiva perfeitamente sintetizada na consideração da literatura como o sorriso da sociedade, como bem percebeu o sentido acurado de Afrânio Peixoto, representante de destaque dessa mesma tendência. Além disso, o que logo se verificou nesse entrecho de nossa história literária foi uma espécie de anseio pela novidade e pela modernidade, traduzindo-se, via de regra, na ampla aceitação de um singular cosmopolitismo literário à D'Annunzzio e Oscar Wilde, que, no Brasil, seria cabalmente representado pelo já citado Afrânio Peixoto e por outras figuras célebres da

\footnotetext{
1 Doutor e pós-doutorando em Letras Clássicas e Vernáculas pela Universidade de São Paulo; é professor do Programa de Mestrado e Doutorado em Educação (Capes 5), na Universidade Nove de Julho (São Paulo); atuou como pesquisador da Biblioteca Nacional do Rio de Janeiro (2012 a 2013) e como pesquisador-residente da Biblioteca Brasiliana Guita e José Mindlin, da Universidade de São Paulo (2016-2017). E-mail: maurisil@gmail.com
} 
mesma época, como João do Rio, Théo Filho, Arthur de Azevedo e Coelho Neto.

Além do formalismo estético, marca prevalente da literatura brasileira na passagem do século, uma das mais peculiares características literárias do período foi a estilização. Embora vago, pois que dotado de uma acepção bastante larga, o termo se refere, em linhas gerais, a uma obstinada tendência à ornamentação e ao artificialismo com a finalidade de obter efeito puramente estetizante. Completa, nesse sentido, a idéia de formalismo, por revelar uma preocupação maior com efeitos ornamentais gerais, não especificamente voltados para o vocabulário: a plasticidade do período, a temática direcionada (como o mundanismo), a adoção de determinadas diretrizes estéticas (como o helenismo/orientalismo), de uma técnica específica (como o artificialismo) etc.

\section{Grécia de cartolina}

Uma das características mais relevantes da literatura academicista daquela passagem de século é a estilização da cultura clássica e oriental, a que podemos chamar de helenismo e orientalismo. Trata-se, em poucas palavras, de uma verdadeira mania por personagens, fábulas, imagens, conceitos, padrões estéticos e motivos próprios das civilizações grega, persa, egípcia e outras.

Essa atmosfera peculiar de um período afeito a falsos eruditismos e a imagens grandiloqüentes é bem descrita por Brito Broca, (BROCA, 1960; BROCA, 1991) em seu estudo sobre a literatura de 1900: segundo o crítico, a partir do advento do Parnasianismo, os deuses do Olimpo readquiriram o antigo prestígío e implantou-se "a hegemonia da Grécia na literatura brasileira". Mas, como afirma o mesmo autor, com uma ressalva: muitos autores "helenizavam de oitiva", tratando-se, portanto, de uma "Grécia de cartolina, puramente decorativa". Dessa moda, sempre segundo Brito Broca, participaram Coelho Neto, Olavo Bilac, Tobias Barreto, Graça Aranha, Dario Veloso (poeta simbolista que, inclusive, fundara um Instituto Pitagórico, destinado ao culto de Pitágoras) e outros. O mesmo crítico reafirma suas opiniões em outras obras, quando lembra que a maior parte dos escritores brasileiros da passagem do século considerava-se grega sem nunca ter ido à Grécia, comprazendo-se em "ostentações enfáticas", resultado de uma indefectível "mania de citar os gregos". 
Semelhante diagnóstico de nossas letras é proferido ainda por Agrippino Grieco, para quem existiria, por essa época, uma tendência à idealização da Grécia, levada a cabo pelos "hellenistas de compendio". E completa:

\begin{abstract}
póde mesmo dizer-se que cada um de nós tem uma Grecia para seu consumo pessoal, cada qual a vê com a côr das suas lunetas, cada qual a augmenta ou diminue ao sabor de sua literatura (...) A maioria procura uma zona de museu e de archivo, de theatro classico, uma zona de universitarios em férias, uma zona de estampas e sonetos, effeminada, pretenciosa, uma Grecia que é em Portugal a dos arcades e no Brasil a dos parnasianos (GRIECO, 1931, p. 38).
\end{abstract}

Evidentemente, os críticos citados estão se referindo a um helenismo estilizado, artificial, forjado a partir de uma assimilação mutilada e superficial de conceitos ligados às civilizações clássicas. Enfim, de um helenismo para uso literário, particularmente de uma literatura de entretenimento, sem compromissos nem mesmo com a verossimilhança dos acontecimentos e das personagens, já que, não raras vezes, há um evidente exagero nas descrições das cenas e dos figurantes, tomando-se como modelo um padrão clássico desvirtuado, como veremos em seguida. Não se trata, portanto, da idéia, relativamente comum nos estudos literários, de aticismo, que se caracteriza, como quer José Veríssimo (VERÍSSIMO, 1907) - contrariamente à de helenismo - pela clareza, sobriedade, parcimônia e simplicidade estilísticas.

Curiosamente, é Humberto de Campos - acadêmico assumido e que igualmente apurou sua pena nas tintas desbotadas desse classicismo artificial quem retrata e satiriza, numa fábula emblemática, esse "helenismo de oitiva" de que nos fala Brito Broca. Dedicada, ironicamente, "a um erudito greco-latino que não sabe nem grego nem latim", a fábula narra o encontro de um sabiá com um xexéu, dois pássaros comuns em diversas regiões brasileiras, os quais entabulam um curioso diálogo: estranhando a extravagância do canto do xexéu, uma mixórdia de sons indistintos, o sabiá enfim pergunta acerca de "uns cantos desconhecidos", entoados por aquele, nunca antes ouvidos nas selvas brasileiras; ao que o pássaro inquirido responde tratar-se de sons que pertencem a "espécies extintas", ou seja, aos "dos gansos do Capitólio, da fênix, do pássaro Rok, do pavão de Juno, da águia de Zeus, do mocho de Minerva, do pombo de Venus, 
grasnos, arrulhos, gritos, gemidos, vozes de um mundo alado que se extinguiu". Diante dessa resposta, o sabiá questiona ainda se o xexéu alguma vez ouvira, de fato, os sons emitidos pelas aves citadas, recebendo uma negativa como resposta. Então, profere esta admoestação:

por que não cantas sem vaidade, sem pedanteria, sem alarde, com os sons naturais da tua garganta excelente, estes crepúsculos melancólicos, esta poeira triste com que o céu polvilha a verdura desfalecente das folhas, e estes rumores da noite, estas vozes selvagens que deviam ser ouvidas religiosamente por todos os ouvidos reverentes da terra? Sê da tua selva, da tua mata, ave da tua árvore, pássaro do teu ramo... (CAMPOS, 1945, p. 139).

Percebe-se, nessa fábula, uma crítica aos helenistas de arremedo, àqueles que, embora se esmerem em entoar cânticos exóticos, sobretudo provenientes da Grécia clássica, não sabiam "nem grego nem latim", por pouca experiência prática ou desconhecimento teórico da matéria. Criticavam-se, a bem dizer, os estilistas das civilizações antigas, aqueles que, pelo tema abordado ou pela forma empregada, buscavam um efeito literário que os fizesse herdeiros tardios da tradição cultural greco-romana.

Críticas, aliás, não faltavam a esse modismo, vindas de todos os tipos de personalidades da época, sejam acadêmicas - ainda que apenas num primeiro momento -, como José Veríssimo, Graça Aranha ou, conforme acabamos de ver, o próprio Humberto de Campos; sejam assumidos antiacadêmicos, como Antônio Torres e Lima Barreto.

Este último destaca-se como o mais acirrado crítico da tendência helenizante que tomou conta dos acadêmicos. Em sua conferência intitulada "O Destino da Literatura", Lima Barreto afirma que a literatura deve-se orientar pelos ideais humanistas e não por "ideais arcaicos e mortos, como este variável e inexato que a nossa poesia, tanto velha, como nova, tem por hábito atribuir à Grécia", (BARRETO, 1956a, p. 58) criticando aqueles a quem chama de "helenizantes de última hora". (BARRETO, 1956a, p. 62) Também no prefácio intitulado "Amplius!", de seu livro Histórias e Sonhos (1920) - prefácio, aliás, no qual se inspirara para escrever a conferência aludida -, o romancista carioca faz um desabafo quase pessoal, ao afirmar: "implico solenemente com a Grécia, ou 
melhor: implico solenemente com os nossos cloróticos gregos da Barra da Córda e pançudos helenos da praia do Flamengo". (BARRETO, 1951, p. 12)

Críticas contundentes a essa adoção indiscriminada e artificial do classicismo greco-latino pelos acadêmicos também provinham de autores que conviveram próximos à Academia. É o caso, para citar apenas um exemplo, de Graça Aranha que, em conferência proferida durante a década de 1920, ecoando a sentença de morte da Academia já anteriormente apregoada por ele mesmo, decretava peremptoriamente: "os mythos gregos estão mortos". (ARANHA, 1932, p. 77).

Em meio a estas críticas episódicas, o helenismo percorria sua trajetória invicta entre os academicistas. E tanto mais vitorioso ele se manifestava quanto mais afeito aos preceitos academicistas fosse o autor.

É o caso de Coelho Neto...

A ligação desse autêntico primus inter pares da Academia Brasileira de Letras com o helenismo era uma atitude deliberada, não apenas pela freqüência com que aparece em seus escritos, como também por alguns indícios deixados pelo romancista de que essa seria uma maneira pessoal de exprimir-se literariamente. Esse seu apego ao helenismo pode, por exemplo, ser depreendido das palavras de Anselmo, alter ego do autor, em seu romance $A$ Conquista (1895):

A Grecia com os seus deuses e com os seus heróes, a India com os seus mysterios... Isso sim! Sinto-me arrastado para essas idades (...) Amo o antigo e esse entranhado amor faz com que eu acredite na metempsychose. Eu fui grego, pelejei nas Thermopylas... (NETO, 1920, p. 17).

Em Coelho Neto a devoção ao helenismo espalha-se por toda a sua obra, das crônicas aos contos, atingindo vários romances do autor, com pequenas ou grandes referências à realidade ática, dando sustentação às suas figuras, à sua linguagem, aos seus exemplos. É possível, neste sentido, observar tais referências em $O$ Morto (1898), num trecho que procura descrever a figura feminina: 
seus cabellos fartos faziam-Ihe sobre a cabeça uma pequenina torre de ouro. Levou-me logo para a sala, desolada como Andromacha, no poema de Homero, quando corre a molhar de pranto o corpo amado do esposo que vem sangrando no escudo trazido piedosamente pelos guerreiros fiéis (NETO, 1924a, p. 124);

ou em A Capital Federal, numa passagem significativa pela enumeração de personalidades gregas:

mas creia o amigo que é só assim que consigo comprehender e explicar a apparecimento dos homens cyclicos - Homero, que é a synthese de todo o drama épico desde o período pelágico; Hesiodo, que é o mytho, a theogonia; Eschylo e Sophocles, que são a tragedia... (NETO, 1924, p. 142).

É evidente a tentativa de Coelho Neto de dotar parcialmente os seus romances de uma atmosfera helênica. Esforço que encontra ressonância nas próprias teorias estéticas de um autor habituado com a mesma atmosfera desde a infância. ${ }^{2}$ Desse modo, o romancista não perde a oportunidade de inserir em suas obras referências freqüentes às civilizações antigas, com cenas, personagens, ambientação e imagens retiradas do clacissismo grego.

Nesse sentido, qualquer assunto poderia ser motivo de referência ao passado glorioso dos clássicos helênicos, mesmo os mais prosaicos, como se pode perceber em muitas de suas crônicas mundanas, escritas diariamente para as folhas voláteis dos periódicos da época. Tratando, por exemplo, da primeira experiência do correio aéreo na Itália, o romancista não hesitava em fazer referência a Zeus, Mercúrio, Fênix, Éter e outros; como não hesitava também em se referir a Pausânias, Júpiter e ao pentatlo, ao tratar da difusão das lutas de boxe no Brasil; enfim, a uma série de personagens da cultura grega, como se pode perceber neste trecho de crônica que trata da viagem de um navio europeu à América:

Se Apollonio de Rhodes celebrou no poema, a cuja chamma se aqueceu a musa de Virgilio, os feitos dos argonautas, motivos mais bellos para

\footnotetext{
2 Ver, nesse sentido, entrevista de Coelho Neto ao Jornal Pequeno, de Recife, e à Gazeta de Notícias, do Rio de Janeiro, onde o autor confessa expressamente ter sido influenciado por histórias fantásticas envoltas, via de regra, por uma atmosfera francamente ática e oriental (apud TAVARES, Adelmar. "Ouvindo Coelho Neto". Autores e Livros. Suplemento Literário de "A Manhã", Rio de Janeiro, Vol. IV, No. 12: 179, Abril 1943).
} 
mais altos cantos achará um poeta na expedição do 'Itália' para com elles glorificar a terra e a gente de Latino (...) A náo construida no estaleiro argivo, com madeira de Dódona, sob a immediata direcção de Pallas, fez-se ao mar em cruzeiro de conquista, demandando a Colchida, e nella o ouro do velocino (...) A guarnição heroica fôra toda escolhida pela deusa - desde o chefe: Jasão, até o piloto: Palinuro e, entre esses, andavam muitos que, pelos feitos com que se celebrisaram, subiram além da Historia, inscrevendo-se no céu, no rol das constellações, como os gemeos e Héracles; e, ainda Anphiarau, o advinho, Theseu, o vencedor da górgona e o poeta mystico do Tempé, dominador de almas, dos brutos e da natureza (NETO, 1928, p. 218).

A crônica continua com referências a outras figuras mitológicas (como Argos e Orpheu), sempre nesse mesmo compasso grandiloqüente e épico. Como se pode perceber, não são poucas as personagens clássicas que povoam os textos de Coelho Neto, já que aqui demos apenas uma pequena amostragem desse procedimento na produção ficcional do romancista maranhense.

A insistência com que empregava tais recursos gerava uma verdadeira enxurrada de críticas, muitas vezes pessoais, a sua obra. O próprio Lima Barreto, já citado anteriormente, tratava-o com carregada ironia, ao dizer por exemplo que o célebre acadêmico teria "exum(ado) os gregos com seu cânon de beleza", para completar irado: "é preciso acabar com essa história de Grécia...". (BARRETO, 1956b, p. 87)

Outro crítico não menos contundente, Antônio Torres, referia-se ao uso excessivo desse recurso por Coelho Neto como sendo uma "hellenice descabida", e - numa referência à viagem do Rei Alberto, da Bélgica, ao Brasil - ironiza, dizendo que o ilustre visitante corria o risco de ser recebido pelo nosso romancista oficial e ser chamado de

Hercules, Achilles, Charonte, Niebelung, Apollo de Delphos, Jupiter Amon, Zeus, filho da Stygia, vendedor do Acheronte, rival de Pompeu, heroe da Pharsalia; depois [Coelho Neto] comparará a Augusta Consorte de V. M. com Venus de Cnido, Diana de Epheso, Pallas Athenéa, Eleusis, Salambô, Dido, as camphoras, estatua de Tanagra, Lysistrata, Circê, Astartê, Gorgona, Helena de Sparta, Hygia e Clytemnestra (TORRES, 1921, p. 96).

José Veríssimo, finalmente, um dos companheiros de Coelho Neto na Academia, num texto particularmente brilhante, mantendo sua proverbial independência de opinião, criticou esse exagero do ilustre confrade, ao afirmar 
que

o Sr. Coelho Neto não é, como erradamente se julga, nem um Heleno, nem um primitivo (...) O que no mundo helênico, na obra literária da Grécia o seduz, o que ele sobretudo estima e aprecia, são os seus lados românticos, as exterioridades espetaculosas, os aspectos trágicos, romanescos, e mais o brilho, o colorido (VERÍSSIMO, 1977, p.11).

A crítica talvez servisse, em proporções menores, a outros acadêmicos de nomeada, igualmente adeptos de toda sorte de helenismos de efeito, como Humberto de Campos, que na crônica com que abre seu volume Os Párias, procura tratar dos problemas que envolvem a condição do escritor profissional invocando uma miríade de personagens da Grécia clássica:

Em Salamina, investem as triéres, das quais sobem os cantos harmoniosos dos gregos, e os gritos confusos dos bárbaros. Temístocles e Aristides, Euribíades e Filácio, Polícrito de Egina e Teomestor de Samos, realizam prodígios de bravura e de agilidade. Da sua torre de madeira, á margem do mar, é em Artemísia, rainha de Halicarnasso, que Xerxes, senhor da Asia, tem os olhos. A coragem daquela mulher 0 assombra tanto, que êle já déra, na véspera, o seu nome á costa setentrional da Eubéa... (CAMPOS, 1933, p. 07).

Não nos alonguemos mais... A referência, com comparações entre a situação de alguns personagens e a do próprio escritor, estende-se por outros longos parágrafos, citando ainda Mardônio, Agamenon, Briseida, Aquiles, Tróia, a Ilíada etc. Como Coelho Neto, Humberto de Campos era também afeito aos recursos oferecidos por esse típico helenismo fin-de-siècle.

Outros acadêmicos de renome, como Rui Barbosa, igualmente os empregavam, como quando, num texto sobre o poeta Castro Alves, o jurista constrói sua rede de argumentos a partir de figuras apreendidas da mitologia grega, citando Phidias, Athene, o Parthenon, Minerva, o Olympo, Iris, Victoria, Jupiter e outros; ou como Hermes Fontes que, embora não fizesse formalmente parte da Academia, era um dos mais atuantes poetas nas duas vertentes estéticas características do academicismo, o neoparnasianismo e o neosimbolismo. Num texto em que comenta a situação política contemporânea na Grécia, Hermes Fontes resume aquele que poderia ser tomado como sentimento 
emblemático dos academicistas em relação à cultura helênica:

A Grecia não é simplesmente uma pequena patria, a desapparecer em silhueta vaga e funebre (...) É, bem mais do que isso - a Patria de todas as patrias, um exemplo permanente, uma reliquia semiviva, [um] museu sagrado (...) Todos os homens civilizados e cultos somos gregos transplantados, brotos de enxerto em patrias novas disseminadas pela Terra (FONTES, 1916, p 190).

Aflora, nessa pequena passagem, uma espécie singular de ideologia genesíaca, que fixa a cultura helênica como origem de todos os homens civilizados; e que, além disso, acaba por considerar a ligação com os gregos a partir de uma perspectiva religiosa, por meio da qual o Brasil deve sua existência a um sagrado ritual de fundação. Por essa ótica, seríamos fruto de uma epopéia universal, "condenando-nos" a uma sempiterna relação de dependência para com a civilização helênica. Pensada num país mestiço, recém-saído da escravidão e cuja pirâmide social revelava-se extremamente excludente, essa lógica arrevesada apontaria decerto para uma sintomática tendência aristocrática e autoritária, reforçando ainda mais os vínculos entre a estética academicista e o poder burocrático constituído.

Essa dependência - levada a sério pelos academicistas a ponto de cultivarem-na como um bem sagrado, merecedor do culto literário - teria ficado como um lastro cultural permanente na civilização. Daí lançarem mão - quase que indiscriminadamente - de temas e motivos de extração clássica. Semelhante pendor não se verificava apenas tematicamente, como nossa análise pode levar a imaginar, mas também formalmente, por meio do emprego de um estilo descritivista e dramaticamente grandioso, marcando suas obras com pendores épicos, sempre com a mesma correção gramatical e perfeição lingüísticas que caracterizaram a inclinação formalista dos acadêmicos. A vinculação, aliás, da idéia de helenismo à de perfeição linguistica e gramatical já estava presente na antigüidade clássica, já que, nas palavras de uma estudiosa do assunto -

o helenismo não é (...) o uso assistemático, variado e ocasional (...) ele é, sim, o denominador constante, regular e regrado (...) Tudo o que está fora do modelo da linguagem correta e recomendável é excluído (...) Linguagem correta, considerada padrão, o helenismo é a concretização da analogia lingüística. O problema da analogia em si e por si é lógico, 
mas a analogia, passando para o terreno lingüístico como tal, concretizase no padrão que representa o helenismo e chega a significar a própria língua grega. A exposição dos fatos dessa língua é, afinal, a gramática (NEVES, 1987, p. 98).

É ainda em Coelho Neto que podemos encontrar alguns dos mais significativos modelos desse estilo que, influenciado pelo apego à tradição helenista na literatura do entresséculos, primava por uma linguagem moldada pela grandiloqüência vernacular. Vejamos, a título de exemplo, duas descrições de uma tempestade, retiradas primeiro de O Morto:

Falavamos quando uma rajada tempestuosa estortegou o arvoredo em convulsão de cataclismo. O céu fulgurou em esplendor de explosão e um estrépito retalhou os ares taciturnos como ao rebentar de uma granada (...) Grossas gotas de chuva bateram na terra com força, levantando poeira (...) Clarões alumiavam o espaço turbado e sinistro, coriscos ziguezagueavam pelos nimbus como as derradeiras faúlhas que serpentinam rápidas em papel queimado. Bateram janelas, caiu uma grande sombra e o aguaceiro jorrou em dilúvio, grosso, cerrado, escachoante ((NETO, 1924a, p. 220);

e depois de Miragem:

Lá fóra na grande noite a chuva torrencial alagava os campos, rolava em enxurros pelos vallados; os ventos vergavam os galhos, retorciam-n'os estrondosamente. As arvores debatiam-se em convulsões freneticas, agitando fantasticamente os ramos em movimento de agonia e de desespero, sob a tormenta implacavel. As vidraças afogueavam-se em clarões lívidos de relampagos. Ás subitas, como em derrocada, estrépitos de raios atroavam o espaço (NETO, 1921, p. 64).

As imagens grandiosas e fortes; o apego trágico a que aludiu - logo acima - José Veríssimo; o acúmulo de verbos particularmente expressivos (estortegou, fulgurou, retalhou, rebentar, bateram, jorrou, rolava, vergavam, retorciam, debatiam, atroavam); o emprego de expressões espetaculares e pictóricas, que, entretanto, não escapam ao clichê (LAPA, 1975) (rajada tempestuosa, convulsão de cataclismo, esplendor de explosão, chuva torrencial, convulsões frenéticas, tormenta implacável, estrépitos de raios); os torneios frasais, sempre balizados pelo uso enfático de alguns adjetivos (taciturnos, turbado, sinistro, cerrado, escachoante, lívidos) e advérbios (estrondosamente, 
fantasticamente); tudo, enfim, parece contribuir para um efeito estilístico marcado por um sopro épico, dando à sua prosa aqueles inegáveis "acentos de epopéia" de que nos fala Fernando Azevedo, ao tratar das obras de Coelho Neto. (AZEVEDO, 1962, p. 135)

Além desse visível apego ao helenismo, os autores academicistas também apresentavam clara tendência às temáticas de extração oriental (egípcia, persa, nipônica etc.), ainda empregando-as como mero artifício literário, recurso aliás comum também aos autores europeus desse período. (LITVAK, 1990) Em Coelho Neto esse orientalismo é deliberado, assumido como princípio estético que norteia toda sua produção ficcional. É esclarecedor, nesse sentido, um trecho de seu roman-à-clef intitulado $A$ Conquista, em que o autor inventa um diálogo entre os personagens Anselmo (Coelho Neto) e Ruy Vaz (Aluísio Azevedo). Após o anúncio, por Anselmo, da publicação de mais um romance de sua lavra, em folhetins na Cidade do Rio, Ruy Vaz o aconselha a abandonar "essa mania de orientalismo", admoestando-o a deixar em paz "os deuses gregos e as odaliscas turcas" e a não se preocupar com "os templos da Hellade nem com os minaretes de Stambul". A resposta de Anselmo é quase uma profissão-de-fé literária:

comecei a estudar com livros orientaes (...) e hoje sinto que, se deixar o Oriente, fico como um homem que, trazido vendado, se achasse, de repente, como por encanto, num intrincado labyrintho donde não pudesse sahir por desconhecer os meandros (NETO, 1920, p. 380).

A "mania" a que Aluísio Azevedo alude perpassa quase que integralmente a obra de Coelho Neto, autor capaz de dar a um romance de temática regional, quase indígena, o sintomático título de O Rajá de Pendjab (1898) (NETO, 1927); de descrever os aposentos de uma casa carioca, comparando-os "aos palacios maravilhosos de Aladino e á soberba vivenda de Sindbad"; (NETO, 1924b, p. 45) ou ainda de escrever toda uma fábula ambientada num indefinido recanto oriental, entre sacerdotes, papiro, palácios, cítaras, camelos e outros motivos "orientais". (NETO, 1919, p. 07)

Não sem razão, Humberto de Campos, ao analisar o livro Contos da Vida e da Morte, de Coelho Neto, destacaria justamente sua "ornamentação oriental"; (CAMPOS, 1935, p. 64) e ao analisar seu livro Bazar - cujo título, nesse sentido, é 
bastante sugestivo -, além de destacar seu "orientalismo puro", afirma ser o romancista o "último persa". (CAMPOS, 1935, p. 227)

Apenas a título de exemplo, podemos perceber a que Humberto de Campos se referia quando aludia a essa particularidade do fazer literário de seu companheiro de Academia, nesta descrição de uma residência retirada do já aludido O Rajá de Pendjab:

diante da porta, duas altissimas pyramides verdes, cercadas de luzes, illuminavam os primeiros degráus alcatifados por um alto e fôfo tapete persa. Hindus enormes, vestidos com sumptuosidade dois dos quaes empunhavam charamellas de prata (...) ali, naquele bosque, ha uma imagem gigantesca de Kali; mais adiante, naquelle palmar, ha um pequeno templo consagrado a Brahma e, á beira da agua, Galga, em um nicho, aceita, todas as manhans, os votos dos seus fieis (NETO, 1927, p. 210/214).

Em matéria de orientalismo, outros autores devotos do academicismo literário também esmeravam-se em dar sua contribuição pessoal. Se pensarmos apenas nas descrições de motivos decorativos que preenchem os espaços por onde circulam personagens dos mais diversos tipos, teremos uma idéia do alcance do que aqui denominamos orientalismo. De fato, é uma profusão de apetrechos orientais, como porcelanas de figuras chinesas, tapetes persas, divãs turcos, caquemonos japoneses, vasos de Kioto, jarras e marfins orientais, esmaltes árabes, mobília indiana, deuses brâmanes de metal, porcelanas persas, tabacos turcos, enfim todo um mundo de quinquilharias do mais exemplar estilo kitsch a povoar os romances de Júlia Lopes de Almeida ( $A$ Intrusa), de Aluísio Azevedo (O Homem, A Condessa Vesper), João do Rio (Dentro da Noite), Benjamim Costallat (Katucha) e outros. Uma decoração, aliás, que fazia parte da vida real de muitos autores, brasileiros e europeus, que atuavam no cenário literário acadêmico do período, como um Olavo Bilac ou um Edmond de Goncourt. (RIO, 1994; BILLY, 1951; SILVA, 1997)

O orientalismo como tema, e não apenas como motivo decorativo, pode ainda ser presenciado na prosa de ficção de Humberto de Campos ( $A$ Sombra das Tamareiras. Contos Orientais, 1934) (CAMPOS, 1934a); ou na de Júlia Lopes de Almeida - essa "primeira-dama da Belle Époque brasileira", o que a coloca como o mais acadêmico dos escritores fora da Academia (SHARPE, 1999) -, 
como em Ância Eterna (1903), que possui um conto inteiro passado no antigo Egito, entre papiros, sacerdotes, princesas, túnicas, escravas, faraós e sarcófagos. (ALMEIDA, 1903) Com efeito, ao lado da Grécia, o Egito emergia como a região mais literariamente freqüentada pelos escritores academicistas, consolidando-se na época uma verdadeira egiptomania. O termo é do cronista carioca Gastão Penalva (que, de fato, viajou ao Egito), o qual trata do assunto em mais de uma crônica de seu livro Luvas e Punhaes (1924). Numa delas, lembra que essa febre já tomou conta de praticamente todas as instâncias da vida carioca, do jornalismo à moda, e lamenta:

a mania já attinge a tal ponto que o Rio inteiro me parece o Cairo, Luxor, Port Said ou Alexandria. Tudo é egypcio. O obelisco da Avenida é o sagrado obelisco de Menphis. A Exposição é Gizeh, cheia de monumentos e de forasteiros. A Guanabara é o Nilo poderoso, a explodir nas enchentes victorias e jacarés. A Esphinge... (PENALVA, 1924, p. 200).

Também João do Rio, em mais de uma crônica, lembra o modismo que se tornou o Egito, num incompreensível desprezo pelo Brasil:

Se um cidadão aparecer aqui dizendo-se o fallecido Khediva do Egypto, tem logo a acolhel-o uma roda smart, que terá prazer em se mostrar conhecedora do Nilo, dos antigos coptas, da Esfinge, das piramides - ah! As piramides!... - das avenidas modernas, do Cairo... Brasil é que não, nem rachado! (RIO, 1909, p. 313).

A recorrência aos motivos próprios do imaginário oriental e, particularmente, egípcio era tamanha que transformou - não hesitamos em afirmar - a temática da Esfinge (a qual, embora se tenha disseminado via mitologia grega, guarda uma inegável ligação com o universo cultural do Egito), num autêntico topos do academicismo literário, fazendo-a presente em várias obras do período, além de aparecer como título de algumas delas, como em Francisca Júlia (Esphinges, 1903), em Coelho Neto (Esphinge, 1906) ou em Afrânio Peixoto ( $A$ Esfinge, 1908).

Quase sempre, esse topos estava ligado à figura feminina, servindo de referência para a caracterização de mulheres fatais, enigmáticas, às vezes diabólicas, quase sempre indecifráveis. É o que acontece, por exemplo, com as 
mulheres que povoam os contos de João do Rio em seu $A$ Mulher e os Espelhos (1919), para quem "as mulheres são esfinges". (RIO, 1995, p. 85) A aproximação da mulher com figuras do universo egípcio é recurso empregado também por outros autores do período, não exatamente cultores da estética academicista, embora não de todo contrários a ela, como é o caso de Albertina Bertha, que em Exaltação (1916) faz Theophilo se referir a Ladice nos seguintes termos: "sempre que a vejo, lembro-me do Oriente. Parece-me antes uma egypcia que uma brasileira". (BERTHA, 1918, p. 160) Como é o caso, igualmente, do escritor lusobrasileiro Carlos Malheiros Dias, autor do polêmico A Mulata (1896), cuja protagonista, Honorina, é descrita como uma autêntica rainha egípcia:

Cleópatra, a Rainha de Sabá, Nimsuba, deviam ser assim como ela era, abrasada pelo sol, de corpo de bronze, como uma deusa, de olhos ardentes como jóias, como o espículo de uma falarica, como na escuridão, bárbara e imperiosa como um beduíno, terrível como uma víbora, indómita como um condor (...) De olhos fechados, sentava-se no trono dos Faraós, entre peles de felinos e sedas roxas bordadas a lotos de oiro (...) Despia-a, trajava-a de rainha de Sabá... (DIAS, 1975, p. 123).

A figura feminina idealizada, extraída da mitologia grega, serve enfim de inspiração para que o mesmo Carlos Malheiro Dias relate sua "profissão-de-fé" num livro inteiramente dedicado à temática helênica e oriental - nos seguintes termos:

os gregos fizeram nascer a sua Venus do ventre espumejante das ondas, e o meu ideal artistico de sonho antigo nasceu da contemplação do teu corpo de marmore, oh! Mulher, que eu julguei roubado a um templo de Athenas ou Coryntho... (DIAS, 1894, p. 193).

\section{Considerações finais}

Se, como dissemos anteriormente, do ponto de vista temático, prevalecem temas como o helenismo/orientalismo, do ponto de vista formal destaca-se um conceito amplo de ornamentalismo, que pode ser entendido, em linhas gerais, como uma tendência ao floreio estilístico, ao retoricismo, ao rebuscamento frásico, à prolixidade. Na literatura desse período, a ornamentação literária se manifestou, muitas vezes, como apego a certos aspectos da estética 
art nouveau, tendência artística vitoriosa durante a Belle Époque.

Dissemos "certos aspectos", pois, a rigor, a estética art nouveau - que se caracteriza pela busca de uma nova linguagem artística, inspirando-se nas formas orgânicas da natureza, privilegiando o domínio da sensação e do misticismo, apelando para o ornamento e para o decorativismo e tendo como temáticas privilegiadas a natureza e a mulher - é fundamentalmente antiacademicista. (CHAMPIGNEULLE, 1976; VERNEUIL \& AURIOL, 1974; WALTERS, 1974) Combatendo, até certo ponto, a superficialidade e o conservadorismo artístico, ela buscava diferenciar-se de modo cabal da arte acadêmica, sobretudo no que concerne às artes plásticas, mas também à literatura. As coincidências entre o academicismo e a estética art nouveau, portanto, limitam-se ao aspecto da ornamentação, o que pode ser percebido, do ponto de vista gráfico, numa simples leitura das revistas literárias e/ou mundanas que circulavam no período: tanto as revistas de inclinação antiacadêmica (como Fon-Fon, O Malho ou Careta) quanto as de pendor visivelmente acadêmico (como Renascença, Kósmos ou a Revista da Semana) primavam pela valorização do ornamentalismo gráfico, com seus frisos geométricos, suas molduras florais, seus motivos naturais, seus contornos acentuados, suas estampas espiraladas... Tudo devidamente estilizado. (OLIVEIRA, 1997; ORLOV, 1980; PAIVA, 1992; FILHO, 1999; DIMAS, 1983)

No fundo, era mesmo esta fièvre ornamentale de que fala Delevoy que acabava contando para os escritores, os quais procuraram, sobretudo na perspectiva da forma, adaptar conceitos do artenovismo à expressão literária academicista, tornando mais efetivo o imbricamento entre as artes plásticas e a literatura. (DELEVOY, 1958; HELD, 1981; MOTTA, 1957; ZANINI, 1983; LIMA, 1985)

Críticos como Alfredo Bosi consideram o art nouveau uma das marcas mais salientes da Belle Époque literária, manifestando-se como uma prosa estilizada e ornamental:

dos fins do século à guerra de 1914-18, a corrente mestra de nossa literatura, a que vivia em torno da Academia, dos jornais, da boêmia carioca e da burocracia, admirou supremamente esse estilo floreal, réplica nas letras do 'art nouveau' arquitetônico e decorativo que então exprimia as resistências do artesanato à segunda revolução industrial (BOSI, 1988, p. 220, grifo meu). 
Trata-se, em poucas palavras, daquele "esplendor art nouveau" de que nos fala Brito Broca; (BROCA, 1960) ou, para citar apenas mais um estudioso do assunto, da "exuberância ornamental" referida por José Paulo Paes, no mais consistente trabalho sobre a influência da estética art nouveau nas letras brasileiras. (PAES, 1985)

Não é difícil, nesse sentido, perceber a dívida de alguns dos mais representantivos acadêmicos - ou que com eles estabeleciam uma nítida relação de proximidade estética - para com a expressão art nouveau, seja pelo emprego de temas próprios dessa tendência, como o mundanismo estilizado, e a procura de efeitos estilísticos (caso de um João do Rio ou um Benjamim Costallat); seja pela obsessão por torneios frásicos e pelo retoricismo ornamental (caso de Coelho Neto ou de Xavier Marques). (PAES, 1985; SECCO, 1978; GENS, 1995; LOPES, 1994; SALLES, 1977)

Mas nem todo ornamento provém da estética art nouveau. No Brasil sobretudo entre os academicistas - tivemos, por exemplo, a prosa ornamental de Rui Barbosa, proveniente antes de seu retoricismo jurídico, ou a de Coelho Neto, nascida também de uma obstinada procura pelo linguajar preciosista e pelos efeitos de estilo; em muitos aspectos, diferente da escrita de um João do Rio ou de um Benjamim Costallat, cujos ornamentos deviam muito ao formalismo difundido pela Arte Nova.

Torneios frásicos, períodos prolixos, orações rebuscadas, excesso de subordinação nos parágrafos, efeitos de estilo, copiosidade vocabular... Essas eram as marcas predominantes do discurso academicista de feitio ornamental. Tudo se resumia, no final das contas, em uma questão de estilo, afirmando-se, por um lado, aqueles que, como Coelho Neto, defendiam a "disciplina de estylo" (NETO, 1913, p. 111) e, por outro, aqueles que, como Lima Barreto, condenavam as "chinesices de estilo", ambos os conceitos empregados aqui no sentido de pomposidade e variação. (BARRETO, 1956무 p. 75)

Esses floreios sintáticos, esse discurso rebarbativo, essa dicção oratória e clacissizante fazem parte de um estilo ornamental próprio dos acadêmicos afeitos a um deliberado empolamento frásico, a um arroubo épico premeditado, a uma adjetivação exuberante e diversificada e a um vocabulário particularmente rebuscado. Mas não se trata apenas de pomposidade e rebuscamento, senão de 
prolixidade, o que redunda num estilo empolado, como se pode perceber também nos contos de Coelho Neto:

\begin{abstract}
Mal aparecesse solemne, pisando firme nos cothurnos classicos, envolto nas dobras da tunica com que Platão, passeiando lentamente entre os tumulos dos heróes e os plátanos, no Ceramico, falava à sadia juventude atheniense de coisas altissimas e puras, o garoto inexoravel daria immediatamente o alamiré e a multidão, que afflue ao ridiculo como as piranhas atiram-se em cardume ao animal que ousa atravessar os rios que ellas dominam, principalmente se leva ferida aberta ou lanho em sangue, por-lhe-ia cerco e o teu heróe, com toda a sua graça apollinea, só conseguiria sahir das aperturas se a Policia, avisada, mandasse em seu socorro uma 'viuva alegre' guarnecida de praças de armas ambaladas (NETO, 1922, p. 54).
\end{abstract}

Empregando o recurso do hipérbato, aliado à subordinação continuada $\mathrm{e}$ a orações intercaladas, o autor logrou criar um parágrafo particularmente complicado, cujos núcleos são algumas orações coordenadas aditivas ("o garoto inexoravel daria immediatamente o alamiré"; "a multidão (...) por-lhe-ia cerco"; "o teu heróe só conseguiria sahir das aperturas"), que receberam uma série de intercalações e subordinações, criando o chamado período complexo misto.

O estilo ornamental se manifesta também, entre os acadêmicos, por descrições que primam pelos efeitos fônicos, como a aliteração, bastante sugestiva neste pequeno trecho retirado de Tapera (1911) de Alcides Maya:

Ondulava-as ainda a brisa a grandes trechos; em diamantadas cambiantes, rorejava-Ihes o orvalho no folhame lentescido; e quer sôbre as mais altas, desdobrando à luz, esbeltas, os pendões, quer nas que, entrelaçadas, alastravam as leivas, havia revôos precípites de pássaros, êxodos minúsculos de insetos, todo um quadro vivo de asas desatadas e frementes elitros multicores (MAYA, 1962, p. 53);

ou neste de Terras Mortas (1936) de Xavier Marques:

Por toda a parte atalhos sombrios, soturnos caminhos outrora rechinantes de rodagem, verêdas que foram transito de boiadas e de alegres tropeiros, tudo atufado sob a flora mesquinha, rispida e semimorta dos carrascais (MARQUES, 1936, p. 127).

Há uma profusão de onomatopéias, com o objetivo de criar um efeito 
sonoro flagrante: "brisa a grandes trechos", "rorejava-Ihes o orvalho no folhame", "entrelaçadas, alastravam as leivas", "revôos precípites de pássaros", "asas desatadas e frementes elitros multicores", "atalhos sombrios, soturnos", "rechinantes de rodagem", "transito de boiadas e de alegres tropeiros, tudo atufado", "rispida e semimorta dos carrascais". Mais um indício claro da preocupação dos academicistas com a estilização literária por meio da ornamentação e outros efeitos congêneres.

Como já destacou, com particular acuidade, Flora Süssekind,

nos primeiros tempos do século $X X$ (...) a opção pelos ornamentos retóricos foi uma das formas mais freqüentes com que se tentou delimitar o campo do 'literário', do 'artístico' em oposição aos processos técnicos de produção e difusão de imagens e vozes (SÜSSEKIND, 1987. p. 57).

Eis aí palavras que resumem bem não apenas as algumas tendências estéticas das tendências analisadas, mas espírito literário de toda uma época.

\section{Referências bibliográficas}

ALMEIDA, Júlia Lopes de. Ância Eterna. Rio de Janeiro, Garnier, 1903.

ARANHA, Graça. Espírito Moderno. São Paulo, Nacional, 1932.

AZEVEDO, Fernando. Máscaras e Retratos. Estudos Literários sobre Escritores e Poetas do Brasil. São Paulo, Melhoramentos, 1962.

BARRETO, Lima. Histórias e Sonhos. Rio de Janeiro, Gráfica Editora Brasileira, 1951. Impressões de Leitura. São Paulo, Brasiliense, 1956a. Marginália. São Paulo, Brasiliense, 1956b.

BERTHA, Albertina. Exaltação. Rio de Janeiro, Jacintho Ribeiro dos Santos, 1918. BILLY, André. L'Époque 1900 (1885-1905). Paris, Jules Tallandier, 1951.

BOSI, Alfredo. História Concisa da Literatura Brasileira. São Paulo, Cultrix, 1988.

BROCA, Brito. A Vida Literária no Brasil. 1900. Rio de Janeiro, José Olympio, 1960. 
Naturalistas, Parnasianos e Decadistas. Vida Literária do Realismo ao Pré-Modernismo. Campinas, Unicamp, 1991.

CALMON, Pedro. "Afrânio Peixoto". Revista da Academia Brasileira de Letras, Rio de Janeiro, Ano 46, Vol. 73: 45-51, Jan./Jun. 1947.

CAMPOS, Humberto de. Os Párias. São Paulo, José Olympio, 1933.

José Olympio, 1934a.

. À Sombra das Tamareiras. Contos Orientais. São Paulo,

- Crítica. Primeira Série. Rio de Janeiro, José Olympio,

1935

. Da Seara de Booz. Rio de Janeiro, W. M. Jackson, 1945.

CHAMPIGNEULLE, B. A “Art Nouveau”. São Paulo, Verbo/Edusp, 1976.

COSTA, Jurandir Freire. Ordem Médica e Norma Familiar. Rio de Janeiro, Graal, 1983.

DELEVOY, Robert L. Victor Horta. Bruxeles, Elsevier, 1958.

DIAS, Carlos Malheiro. Scenarios. Phantasias sobre a História Antiga. Rio de Janeiro, Joaquim da Cunha, 1894.

A Mulata. Lisboa, Arcádia, 1975.

DIMAS, Antônio. Tempos Eurforicos. Análise da Revista Kosmos: 1904-1909. São Paulo, Ática, 1983.

FILHO, Armando Ferreira Gens. Visibilidade e Espacialidade: Poetas, Poemas, Livros, Jornais e Centros Culturais entre 1870-1900. São Paulo, FFLCH/USP, 1999 (Tese de Doutorado).

FONTES, Hermes. Juizos Ephemeros. Rio de Janeiro, Francisco Alves, 1916.

GENS, Armando e GENS, Rosa Maria de Carvalho. "A Visita do Inspetor ou o Dublê de Sanitarista". In: COSTALLAT, Benjamim. Mistérios do Rio. Rio de Janeiro, Prefeitura da Cidade do Rio de Janeiro, 1995, p. 09-16.

GRIECO, Agrippino. Vivos e Mortos. Rio de Janeiro, Schimdt, 1931.

HELD, Maria Sílvia Barros de. Considerações Plásticas sobre "Art Nouveau" nos Anúncios Publicitários Ilustrados do Início do Século XX em São Paulo. São Paulo, Eca/Usp, 1981 (Dissertação de Mestrado).

LAPA, M. Rodrigues. Estilística da Língua Portuguesa. Coimbra, Coimbra, 1975. 
LIMA, Yone Soares de. A Ilustração na Produção Literária. São Paulo - Década de Vinte. São Paulo, IEB, 1985.

LITVAK, Lily. España 1900. Modernismo, Anarquismo y Fin de Siglo. Barcelona, Anthropos, 1990.

LOPES, Marcos Aparecido. "Coelho Neto: Devaneios Poéticos na Escrita Art Nouveau". Anais do Quarto Congresso da Abralic, São Paulo, Edusp, Ago. 1994, p. 601-605.

MARQUES, Xavier. Terras Mortas. Rio de Janeiro, José Olympio, 1936, p. 127.

MAYA, Alcides. Tapéra (Cenários Gaúchos). Rio de Janeiro, Briguiet, 1962.

MOTTA, Flávio. Contribuição ao Estudo do "Art Nouveau" no Brasil. São Paulo, s.e., 1957.

NETO, Coelho. Compêndio de Literatura Brasileira. Rio de Janeiro, Francisco Alves, 1913.

. Fabulário. Porto, Lelo \& Irmãos, 1919.

. A Conquista. Porto, Chardron, 1920.

. Miragem. Porto, Cardron, 1921.

Brasil, 1922.

- Conversas. Contos Dialogados. Rio de Janeiro, Annuario do

. O Morto (Memórias de um Fuzilado). Porto, Chardron, 1924a.

. O Polvo. São Paulo, Jornal do Comércio, 1924c.

. O Rajá de Pendjab. Porto, Chardron, 1927.

. Bazar. Porto, Lello \& Irmãos, 1928.

NEVES, Maria Helena de Moura. A Vertente Grega da Gramática Tradicional. São Paulo/Brasília, Hucitec, Editora Universidade de Brasília, 1987.

OLIVEIRA, Ana Luiza Martins Camargo. Revistas em Revista... Imprensa e Práticas Culturais em Tempos de República. 1890-1922. São Paulo, FFLCH/USP, 1997 (Tese de Doutorado).

ORLOV, Martha Lívia Volpe. A Revista do Brasil e a Formação de uma Consciência Nacional. São Paulo, FFLCH/USP, 1980 (Dissertação de Mestrado).

PAES, José Paulo. "O art nouveau na literatura brasileira". Gregos e Baianos. São Paulo, Brasiliense, 1985, p. 64-80. 
PAIVA, Denise Maria de. As Categorias da Literatura Brasileira na Revista do Brasil (1916-9). Assis, Universidade Estadual Paulista, 2 vols., 1992 (Dissertação de Mestrado).

PENALVA, Gastão. Luvas e Punhaes (Contos e Chronicas). Rio de Janeiro, Benjamim Costallat \& Miccolis, 1924.

RIO, João do. Cinematoghrapho (Chronicas Cariocas). Porto, Chardron, 1909.

O Momento Literário. Rio de Janeiro, Fundação Biblioteca Nacional/Departamento Nacional do Livro, 1994.

Cultura, 1995.

. A Mulher e os Espelhos. Rio de Janeiro, Secretaria Municipal de

SALLES, David. O Ficccionista Xavier Marques: Um Estudo da 'Transição' Ornamental. Rio de Janeiro, Civilização Brasileira, 1977.

SECCO, Carmen Lúcia Tindó. Morte e Prazer em João do Rio. Rio de Janeiro, Francisco Alves/Instituto Estadual do Livro, 1978.

SHARPE, Peggy. "O Caminho Crítico d'A Viúva Simões". In: ALMEIDA, Júlia Lopes de. A Viúva Simões. Florianópolis, Mulheres, 1999, p. 09-26.

SILVA, Maurício. "Benjamim Costallat: o Primeiro Autor kitsch da Literatura Brasileira". Ciências e Letras. Revista da Faculdade Porto-Alegrense de Educação, Ciências e Letras, Porto Alegre, No. 20: 101-108, 1997.

SÜSSEKIND, Flora. Cinematógrafo de Letras. Literatura, Técnica e Modernização no Brasil. São Paulo, Companhia das Letras, 1987.

TAVARES, Adelmar. "Ouvindo Coelho Neto". Autores e Livros. Suplemento Literário de "A Manhã", Rio de Janeiro, Vol. IV, No. 12: 179, Abr. 1943.

TORRES, Antônio. Pasquinadas Cariocas. Rio de Janeiro, Livraria Castilho, 1921.

VERÍSSIMO, José. "O Atticismo". In: Que é Literatura? E Outros Escriptos. Rio de Janeiro, Garnier, 1907, p. 59-72.

. "O Sr. Coelho Neto". Estudos de Literatura Brasileira. Quarta Série. São Paulo/Belo Horizonte, Edusp/Itatiaia, 1977.

VERNEUIL, Maurice \& AURIOL, Georges. Art Nouveau Designs in Color. Alphonse Mucha. New York, Dover, 1974.

ZANINI, Walter (org). História Geral da Arte no Brasil. São Paulo, Instituto Walther Moreira Salles, Vol. 1, 1983.

WALTERS, Thomas (ed). Art Nouveau Graphics. New York, St. Martin, 1974. 